\title{
TRENDS IN BIM AND GIS STANDARDIZATION - REPORT FROM THE JOINT ISO/TC59/SC13-ISO/TC211 WG: GIS-BIM
}

\author{
Christian Clemen \\ HTW - Dresden University of Applied Sciences, Faculty of Spatial Information, Dresden, Germany \\ Commission V, WG V/7
}

KEY WORDS: BIM, GIS, Interoperability, Standardization, Technical Report, ISO, OGC, buildingSMART.

\begin{abstract}
:
This paper for the keynotes of the MVPBIM 2022 conference gives an overview of the current standardization efforts in the GIS/BIM context. The motivation for this paper is to strengthen the general awareness of BIM/GIS standardization and to promote the technical report ISO/TR 23262:2021 (ISO/TR) to academia and professional engineers. The ISO/TR was developed by the ISO/TC59/SC13-ISO/TC211 Joint Working Group 14 GIS-BIM interoperability (JWG14) and is presented and discussed in detail. The report identifies barriers and opportunities for BIM/GIS interoperability and suggests further specific standardization efforts. All results of the ISO/TR relate to standardization, not to mathematical foundations nor software products. The ISO/TR shows how diverse the standardization efforts for data structures, services, content and processes are, when it comes to the interoperability of digital twins of the built environment. In conclusion, future trends in GIS-BIM standardization will be anticipated and the need for standardization is shortly presented on two practical examples.
\end{abstract}

\section{INTRODUCTION}

\subsection{Background}

This extended abstract is intended to supplement the corresponding keynote speech at the MVPBIM 2022 conference. The paper gives a descriptive and analytical overview of the standardization of Building Information Modeling (BIM) and Geographic Information System (GIS), that is conducted by the working group ISO/TC59/SC13/JWG14 BIM/GISinteroperability (JWG14). The main result of the standardization project from JWG14 is the Technical Report (TR), published as ISO/TR GIS (geospatial)/BIM interoperability (ISO 23262, 2021) (ISO/TR). The specific perspective of the presented ISO/TR is standardization itself, in particular standardization within the International Standardization Organization (ISO). In this extended abstract, the mathematical foundations, scientific innovations or software products are out of scope.

Information on planned or built structures (buildings, engineering structures) is managed very detailed in BIM software. In GIS, spatial information on topography, route, terrain form, land/property, environment and society is mapped. The two systems are each structured differently but they are not completely disjoint in their universe of discourse and functionality (Beck et al., 2021). This results in the requirement for interoperability between the two systems in the practice of digital planning, construction and operation of infrastructure.

From the user's point of view, the information models, interfaces and tools for recording, managing, analyzing and presenting should be usable without any barriers between the system boundaries. In the eyes of the author (not by the ISO/TR), BIM/GIS interoperability pursues the following user-oriented goals:

- The database for fact-based decisions is digitally reproducible and reliable
- Relevant information is accessible, linked and machineinterpretable

- Every information delivery can be quality assured automatically

- Each piece of information only needs to be entered once

These goals can currently only partially be achieved with BIM and GIS. In recent years, numerous, but also very different, approaches have been scientifically discussed, standardized by administration and industry, implemented by software manufacturers, developed in projects and applied in business processes. This results in the basic requirement of interoperability. ISO JWG14 has taken on this problem and prepared a joint report in numerous in-person meetings and online meetings in the years 2018-2021. During this processing time, thematic sub-working-groups were formed. The titles of the sub-working groups clearly indicate which topics were discussed:

- Background for Professionals and Standardization

- Domain expert communication

- Joint principles for conceptual modeling

- Semantic interoperability

- Spatial referencing

- Geometric representation and topology

- Processes

- Product Handling

The results of the sub-working groups were processed in such a way that they become candidates for suggestions for further standardization work. The convenors Morten Borrebæk (ISO/TC211), Sigve Pettersen (ISO/TC 59/SC 13) and Jacky Chi Ho Lau (ISO/TC 59/SC 13), all representatives for Standards Norway, headed the editorial department and led the many discussions to a good result. 


\subsection{Problem Statement}

The purpose of this extended abstract is to strengthen the general awareness of BIM/GIS interoperability. However, the aim is also to make the ISO/TR known among academics and professional engineers.

This extended abstract address the following problems:

- What is the scope of the ISO/TR?

- Which categories are used to described BIM/GIS interoperability?

- Which barriers and opportunities of BIM/GIS integration have been identified?

- Which specific suggestions for further standardization were given?

The term interoperability usually has a positive connotation. At the same time, what it actually means is not conclusively defined at the phenomenological level. As an example, two different perspectives on the term interoperability are given:

(ISO 11354-1, 2011) considers interoperability as a generic concept to be used by engineering disciplines. The standard very much assumes that interoperability barriers occur on the conceptual, technological or organizational level. In general, it addresses the ability of companies and corporations to communicate and interact effectively within and between them.

In the geospatial community (e.g. (ISO 19101-1, 2014)) the term interoperability is seen more in the context of information and communication technology (ICT): Here, interoperability is the capability to communicate, execute programs, or transfer data among various functional units in a manner that requires the user to have little or no knowledge of the unique characteristics of those units (SOURCE:ISO-IEC-2382-1,212317)

The ISO/TR, presented in this paper, is not as abstract as (ISO 11354-1, 2011), thus it is tailored to the special problem of BIM/GIS interoperability. It serves as a knowledge document for future standardization projects. It may also help to support mutual understanding for each domain and helps both, standardization experts and BIM/GIS-practitioners.

\subsection{Structure of the paper}

The paper has the following structure: This section gives a brief introduction to the topic. In section 2 the relevant academic (2.1) and (pre-)standardization (2.2) work is shortly presented. The main part of this paper is section 3 , which gives a summary of the TR. This main section includes the description of the structure (3.1) and the scope of the ISO/TR (3.2). In more detail the categories of interoperability (3.3), the identified interoperability barriers $(3.4,3.5)$ and opportunities (3.6) are discussed, resulting in three suggestions for further standardization (3.7). The paper ends with section 4 with some personal interpretations and examples by the author.

\section{RELATED WORK}

\subsection{Academic}

The topic of "BIM and GIS" has been scientifically researched for many years and is increasingly being investigated by academia. Recently (Karimi and Iordanova, 2019) made an extensive and systematic literature study, that focuses on construction automation with BIM and GIS information. They found that in the last 20 years the number of scientific papers increased significantly. Most of the studies showed, that that construction industry is suffering from low productivity, compared to other industries. Digitalization in general, BIM and GIS specifically, could increase productivity. However they also state that BIM/GIS integration is challenging due to the different intrinsic focus of the two domains. Also (Herlé et al., 2020, Hijazi and Donaubauer, 2017) give a literature review and describe different levels of interoperability.

Recently a dissertation (Jetlund, 2021) showed the positive impact of cross-domain standardization for infrastructure projects. Jetlund (2021) states that "improved semantic interoperability could be achieved by using the same core concepts in distinct information models. However, a complete harmonization of information models would not be appropriate, as information models from the [...] domains need to describe the real world in different contexts. Therefore, Semantic Web technologies for linking and mapping should be applied for further improvements of semantic interoperability".

(Roxin and Hbeich, 2019) have published comparable approaches that recommend the use of linked data based on existing BIM and GIS standards. It should be noted that the academic work of (Roxin and Hbeich, 2019, Jetlund, 2021) has had a strong influence on the ISO/TR. Further investigations on BIM/GIS linkage (instead of conversion) can currently be found in (Beck et al., 2021). They point out that the creation of specific link relationships is very context-dependent.

The more practical but very comprehensive research project "GeoBIM-Benchmark" was carried out in 2019 and 2020 under the direction of the TU Delft. The project was sponsored e.g. by ISPRS and EuroSDR. The aim of the research was to examine the current status of software systems that can process BIM and GIS data together. The results of this overarching initiative with a large number of participants provide a very good overview of the data exchange between BIM and GIS. The overview article (Noardo et al., 2020) is recommended, also because many other publications may be found within this report. The focus of the GeoBIM benchmark is the investigation of how semantics and geometry can be exchanged "loss-free" in the data formats IFC and CityGML between the Geospatial and AECO domains. As a result, it can be stated that many software systems for BIM and GIS offer basic functionality for BIM and GIS integration. However, the functionality differs significantly in type and quality. Each software must be adapted and configured for special applications.

Georeferencing is a key aspect of BIM/GIS interoperability. The work of (Clemen and Görne, 2019), which was included in the ANNEX $\mathrm{C}$ of the ISO/TR, has a strong influence on the ISO/TR because it provides a comprehensive overview and a classification schema (LoGeoRef 10-50) for georeferencing with the IFC. A detailed study of the different mathematical concepts and effects on BIM calculations can be found in: (Jaud 
et al., 2020). As they focus on BIM projects for infrastructure, they need accurate concepts for georeferencing.

Future Trends on Geospatial Data Management in general are e.g. postulated in (Breunig et al., 2020). In retrospect it is found that "during the last decade, significant progress has been achieved in geospatial data management research", whereby an important milestone was the "advancing GIS/BIM-integration at data, process, and application levels". As trend for the future, they also postulate, that "As basis for BIM and GIS applications, 3D/4D geospatial data management [...][will be a] key concept to support the geometric, topological, thematic, and temporal modeling"

\subsection{Standardization}

Numerous related work also takes place in the standardization and pre-standardization bodies.

Currently, in the geospatial standardization quite big changes take place concerning the well established OGC web standards/APIs that are going to be added and partially replaced by the new OGC API ${ }^{1}$.

These new standards can be used better in distributed IT infrastructures and across domains. Therefore they are major candidates for future GIS/BIM-integration. The bundled activities of OGC's 3D Information Management Working Group are also relevant for the BIM domain. The OGC activities aim to involve the "architecture, engineering, construction, owner, operator" (AECOO) industry.

The (pre-)standardization of BIM is currently very dynamic. E.g. all parts of (ISO 19650-1, 2018) provide a very general BIM project management framework and terminology. Many other emerging standards support ISO19650: (EN 174121, 2020) defines a frame work for granularity, expressed as Level of Information Need $\left(\mathrm{LOIN}^{2}\right)$, the standard (ISO $21597-$ 1, 2020) specifies the exchange for linked document delivers in (information-)container-based BIM infrastructure, naming linked BIM/GIS integration as one of the major use cases.

The current, more service-oriented developments of the BIM Collaboration Format (BCF) as API or OpenCDE will also influence BIM/GIS integration in the future. Last but not least, it should be mentioned that the Industry Foundation Classes (IFC) are continuously developing (van Berlo et al., 2021). The latest versions of the IFC standards point to the direction of infrastructure BIM, with strong links to the geospatial domain.

The most important "related work" is done by the OGC and buildingSMART working group called Integrated Digital Built Environment (IDBE). The sixteen page report "Built environment data standards and their integration: an analysis of IFC, CityGML and LandInfra" (Gilbert et al., 2020) presents disparities that hinder integration, explains fundamental operations that underpin BIM/GIS use cases, gives practical examples for methods of BIM/GIS integration and proposed action points for stakeholder in industry, governmental administration, standardization bodies and academia.

Even if the report is strongly based on the CityGML, IFC and LandInfra standards, it comes to almost identical conclusions

\footnotetext{
1 https://ogcapi.ogc.org/apiroadmap.html

2 The abbreviation LOIN is actually not used in English because of its natural language meaning.
}

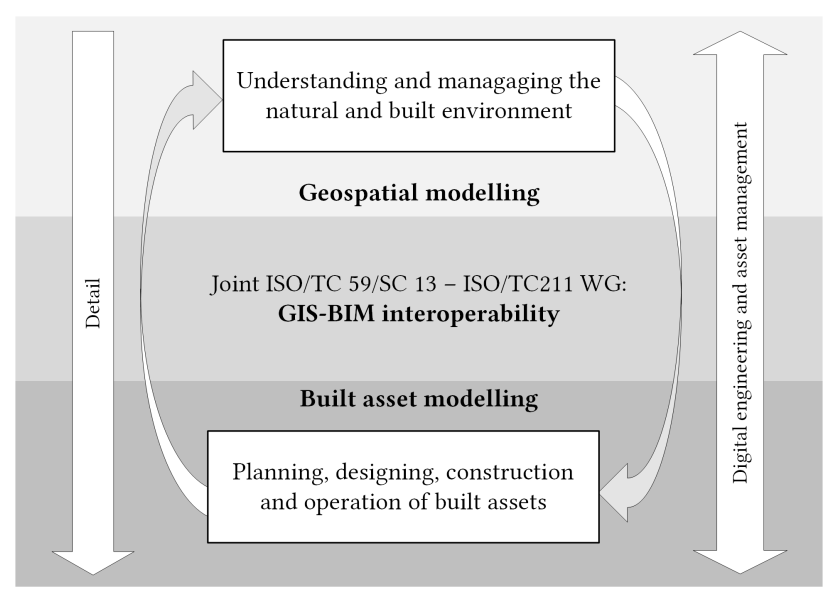

Figure 1. The idealized schematic information cycle demonstrates the need for BIM/GIS interoperability. Figure adopted from (ISO 23262, 2021)

as the ISO/TR presented in this paper. This fact is important in terms of content because two independent bodies worked out very similar action points. At the same time, it shows that the tasks of BIM/GIS can be shared and coordinated across several stakeholder from industry, administration, standardization and academia.

\section{SUMMARY OF THE ISO TECHNICAL REPORT}

\subsection{Structure}

The ISO technical report (ISO/TR) is structured linearly as follows: After the foreword and introduction, the scope (1) is defined. The content of this scope was determined by the member-votes of states. It was therefore instructional task for the working group. As in every standard the normative references (2) are listed and the terms and concepts (3) and abbreviated terms (4) must be given. Since the ISO/TR deals almost exclusively with related standards, section (2) was left blank. The main outcome is presented in the sections Specification of BIM and GIS interoperability issues (5), GIS/BIM interoperability opportunities (6) and - as the main result - Suggestions for further work (7). It must be mentioned that this very clear, linear, argumentation process (5)-(7) is the result of intensive and opinionated discussion groups.

In order to not disturb the readability, some important aspects were thematically addressed in the annex: Handling of information about construction objects (A), IFC and data templates (B), Georeferencing (C) and Spatial representation (D).

\subsection{Scope}

The ISO/TR "investigates barriers and proposes measures to improve interoperability between geospatial and BIM domain, namely to align GIS standards developed by ISO TC211 and BIM Standards developed by ISO/TC59/SC13". Hence, the primary focus was on the standards published by ISO. Nevertheless, it must be clear that a lot of conceptual work is taking place in the area of pre-standardization. Here, the major organizations are buildingSMART international (bSI) for the BIM domain and the Open Geospatial Consortium (OGC) for the geospatial/GIS domain .

The ISO/TR introduction explains the need to standardize interoperability: Both domains, AECOO (architecture, engineering, 


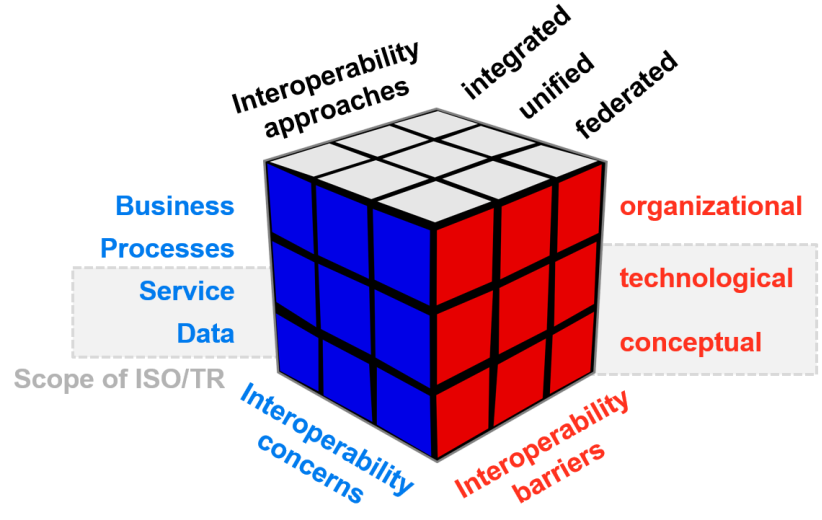

Figure 2. All levels (data, service, process and business) and interoperability aspects as defined by ISO 11354 . The ISO/TR limites the scope to concerns $\{$ service, data $\mathrm{x}$ barriers $\{$ technological, conceptual $\}$.

construction, owner and operations) and geospatial make decisions. These decisions are related to the built environment. Information is created and required by many actors, at many points in time and for the entire life cycle of the built asset. The required data is continuously recorded, managed, transformed and analyzed. However, traditionally AECOO and geospatial have been seen as different domains. This has led to the situation where the two domains use different tools and data formats. Since the experts at the AECOO domain have been increasingly using the BIM method, the boundaries have been blurring. The GIS systems by the geospatial domain must be compatible with BIM software of the AECCOO domain and vice versa.

At the standardization level, it can be seen that the BIM community is currently focusing on the standardization of terms, processes and business models. The geospatial Community, on the other hand, has a very sophisticated set of standards for digital modeling and communication - focusing more on functional standards.

As a result, standards cannot simply be mapped 1:1 between the two domains. Instead, there has to be a detailed examination of the respective standards. This investigation is available with the ISO/TR.

In contrast to the traditional separation an idealized objective is shown in Figure 1: The information can be digitally communicated, cross-domain and with compatible data along life cycle phases and levels of detail.

\subsection{Categorization of Interoperability}

(ISO 11354-1, 2011) was used as a meta-instance independent of BIM and GIS. The purpose this ISO standard is to specify a framework for enterprise interoperability that establishes dimensions and viewpoints to address interoperability barriers, their potential solutions, and the relationships between them. The main phenomenological dimensions of interoperability are shown in figure 2.

The JWG14 found that the framework is very structured and basically suitable. However, not all BIM/GIS problems could be clearly assigned to the framework . Because of this - and also in order not to go beyond the scope of ISO/TR - it was decided to limit the scheme to the levels concerns $\{$ service, data $\} \mathrm{x}$ barriers $\{$ technological, conceptual $\}$. As a consequence of this restriction, the Industry Foundation Classes (IFC, (ISO 167391, 2018)) are examined as the central BIM standard within ISO/TR.

Other important standards such as the BIM management standard (ISO 19650-1, 2018) are referenced in ISO/TR, but they are not in the focus of the investigation. Also current initiatives like an well defined interface for Common Data Environments (openCDE), the API for the BIM Collaboration Format API (BCF by bSI ${ }^{3}$ ), Linked Data Deliveries (ICDD) (ISO 21597-1, 2020), level of information need (LOIN), (EN 17412-1, 2020) and dictionaries for product data (bsDD), bSI international ${ }^{4}$ ) are not covered by the ISO/TR. However, the GIS community shall carefully look at the emerging BIM standards in the future.

Please note, that the different interoperability approaches in Figure 2) are just named in the ISO/TR. This is because the ISO/TR is purely analytic and does not intend to develop new standards. However, it is worth to mention, that, according to the framework for enterprise interoperability from ISO11354 there are three types of approaches to achieve interoperability:

1. integrated

2. unified

3. federated

Integrated approaches (1) convert a domain model into the form of the other models. For example, geodata are transferred to IFC or building models to GML. In practice, numerous "extract transform load" (ETL) technologies are available for this. Unified approaches (2) generalize this process and use a common meta-model for the transformation. The meta model itself is not intended for execution. The most interesting technologically, but still difficult to implement in practice, are federated approaches(3): The information is kept in the original domain model and can be queried via services by anybody, anywhere and anytime. Especially ontologies, which for example are described using the Web Ontology Language (OWL), do a great service, because with formal ontological queries on distributed data sources, formally consistent results can be inferred and delivered.

\subsection{Identified Barriers - MDA}

This extended abstract cannot give a complete list and explanation of BIM/GIS interoperability barriers, identified by the JWG14. Therefore, the argumentation schema and the essential differences between BIM and GIS standards are briefly described.

After the general concepts of interoperability have been presented in the ISO/TR, the two domains are compared. However, the comparison is not that easy, because the standard architecture differs between BIM and GIS. Most GIS ISO-standards are strictly organized according to the concept of model driven architecture (MDA) (ISO 19103, 2015).

\footnotetext{
3 https://technical.buildingsmart.org/standards/bcf/

4 https://technical.buildingsmart.org/services/bsdd/
} 
The layers are:

- Metamodels e.g. UML, general feature model (ISO 19109 2015), etc.

- Conceptual Schema - abstract schema e.g. spatial schema (ISO 19107, 2019), referencing by coordinates (ISO 19111, 2019), etc.

- Conceptual Schema - application schema e.g. EU INSPIRE, OGC CityGML, LandInfra, etc.

- Implementation Schema e.g. schema for GML, OWL, JSON etc. derived from application schema

There is currently no overarching architecture for BIM (comparable to the MDA) that standardizes the development of BIMbased implementations, processes and technologies. However, ISO 16739-1 - IFC was initially based on the STEP architecture and the information model, as described in the standards ISO 10303-201 to ISO 10303-242. These application protocols can be viewed as "conceptual application schemas" for BIM. But still, there is no formal framework that describes how the various BIM standards, e.g. (ISO 12006-3, 2007), all parts of Information Delivery Manual (IDM) (ISO 29481, 2016) and of course the IFC (ISO 16739-1, 2018), relate to one another. This makes it difficult to compare the two domains level by level and equally. Nevertheless, the insurance is undertaken in ISO/TR. A summary of this comparison is given in Table 1. Nevertheless, an attempt was made to compare them in ISO/TR.

In themselves, the Industry Foundation Classes (IFC) provide a layered architecture. These layers are from specific to generic: The domain layer specifies schema for individual domains, the interoperability (shared) layer defines defines concepts that are common for several domains; the core layer defines the basic concepts. The resource layer is different: Not providing inheritance to upper layer, but usage, it is rather a utility layer for basic concepts like geometry, date and time, measures, etc.

There are concepts that are very easy to compare. For example, the IfcObject concept is initially very similar to the GIS feature. The many (simple) concepts of the IFC Resource Layer can also be mapped to specific GIS concepts.

However some concepts are very different in both domains:

- Objectified relationships. Relationships between objects are modeled very differently. While in IFC relationships are objectified, in GIS relationships are expressed more as an association.

- Prototyping. IFC supports prototyping. With the If cType objects it is possible to define an object template once within an IFC document and then to use it multiple times (in a different position). This concept is unusual in GIS.

- Spatial Structure. An essential feature of the IFC is that the spatial structuring is expressed in its own data types, such as IfcSite, IfcBuilding, IfcBuildingStorey, etc. These concepts (redundant in a certain way with the geometry) are unknown in GIS.
The last part of this ISO/TR section states that the ISO standardization for BIM currently knows neither services nor query languages. It must be mentioned that the term "service" in the BIM domain is understood more as a "building service" than as a software / information service. However, the current openCDE project is mentioned, which among other things intends to specify a uniform interface (REST API) for a Common Data Environment (CDE).

\subsection{Identified Barriers - Other incompatibilities}

It turned out that many of the incompatibilities and barriers identified by the sub-working groups cannot be classified in the dogmatic of the MDA level comparison. Instead, reference was made to the simplified scheme of (ISO 11354-1, 2011) for a rough classification. The identified differences and incompatibilities are listed in table 2, which, however, does not claim to be complete.

The table shows that the types of incompatibilities are both versatile and structurally different. Each aspect is described in more detail in the ISO/TR. As the notes in Table 2 indicate, some important incompatibilities are discussed in detail in the ANNEX of the ISO/TR.

The differences presented in this section, which lead to barriers in interoperability, are not necessarily tasks for new standardization projects - they could also be resolved by good practice and good software, for example. It must be mentioned, however, that within the JWG14 there was no clear opinion as to whether (ISO) standardized transformation or linking rules with regard to the geometric and topological representation bring any added value for the construction or geospatial industry.

In order to evaluate the necessity of potential new standardization projects, the following section 3.6 also shows the opportunities of BIM/GIS-interoperability.

\subsection{Opportunities}

Both domains contain elements of information that must be shared with the other domain. The ISO/TR is now examining which elements these are and which measures are possible to eliminate the incompatibilities. A distinction is again made between data and service level.

In the ISO/TR, twelve identified opportunities are shortly described and the related ISO standards are listed. Also the direction $\{\rightarrow, \leftarrow, \leftrightarrow\}$ between BIM and GIS is postulated. The following enumeration is simplified and reordered for readability:

\section{Data-level-opportunities:}

1. Mapping or linking of conceptual schema languages and metamodels (BIM $\leftrightarrow$ GIS)

2. Mapping or linking of conceptual models (BIM $\leftrightarrow$ GIS)

3. Translation for terms and synonyms between the two domains $(\mathrm{BIM} \leftrightarrow \mathrm{GIS})$

4. Guidelines for proper georeferencing of BIM models $(\mathrm{BIM} \rightarrow \mathrm{GIS})$

5. Geospatial Exchange Information Requirements (geoEIR) $(\mathrm{BIM} \rightarrow \mathrm{GIS})$ 


\begin{tabular}{|c|c|c|}
\hline Barrier & GIS & BIM \\
\hline Conceptual Schema languages & UML & EXPRESS and EXPRESS-G \\
\hline Metamodels & $\begin{array}{l}\text { ISO } 19101 \text { (reference model), ISO } \\
19103 \text { (UML profiles), ISO } 19109 \\
\text { (general feature model, GFM) }\end{array}$ & $\begin{array}{l}\text { ISO 10303-201 to ISO 10303-242, } \\
\text { IFC Kernel Schema, ISO } 23387 \text { (data } \\
\text { templates) }\end{array}$ \\
\hline Abstract Concept Schema & $\begin{array}{l}\text { ISO } 19107 \text { (spatial schema), ISO } \\
19111 \text { (coordinate referencing), ISO } \\
19148 \text { (linear referencing), ISO19115- } \\
1 \text { (metadata), etc. }\end{array}$ & $\begin{array}{l}\text { ISO12006-3 (dictionaries), IFC Re- } \\
\text { sources for Geometry, Topology, Date, } \\
\text { Time }\end{array}$ \\
\hline $\begin{array}{l}\text { Conceptual } \\
\text { Schema }\end{array}$ & $\begin{array}{l}\text { LandInfra, OGC CityGML, EU IN- } \\
\text { SPIRE, etc. }\end{array}$ & $\begin{array}{l}\text { IFC Shared Schema, IFC Domain } \\
\text { Schema }\end{array}$ \\
\hline Implementation Schema & $\begin{array}{l}\text { ISO } 19136 \text { (GML), ISO19150-2 } \\
\text { (Rules for OWL), OGC CityGML } \\
\text { schema, etc. }\end{array}$ & $\begin{array}{l}\text { IFC EXPRESS, IFC xml schema, IFC } \\
\text { owl }\end{array}$ \\
\hline
\end{tabular}

Table 1. Summary (and simplification) of the BIM/GIS comparison, structured according to model driven architecture (MDA). BIM standards do not perfectly fit the MDA

\begin{tabular}{lcc}
\hline Barriers / incompatibilities & Conceptual & Technological \\
\hline Differences in underlying software design approach & & $\mathrm{x}$ \\
Differences in geometric/topological dimension of data & $\mathrm{x}$ \\
Generation of watertight B-Reps / high numerical demands in BIM & $\mathrm{x}$ \\
Diversity in spatial representation, e.g. IFC (see also ANNEX D) & $\mathrm{x}$ \\
Semantic incompatibility regarding the concept of "service" & $\mathrm{x}$ & \\
Semantic incompatibility regarding the concept of "product" (see also ANNEX A,B) & $\mathrm{x}$ & \\
Different vocabulary on entities and relations & $\mathrm{x}$ & $\mathrm{x}$ \\
Different extensions of the underlying architectures for addressing semantic interoperab- & & \\
ility issues (open world, closed world) & $\mathrm{x}$ \\
Differences in the usage and specification of coordinate systems (see also ANNEX C) & $\mathrm{x}$ & $\mathrm{x}$ \\
Differences in usage and specification of object geometry and topology (features) & $\mathrm{x}$ & $\mathrm{x}$ \\
Differences in usage and understanding of metadata & \\
\hline
\end{tabular}

Table 2. Additional pragmatic BIM/GIS incompatibilities that are described in the ISO/TR. The table just names the incompatibilities, further information is found in the ISO/TR

6. Quality model for geodata in BIM projects (BIM $\leftarrow$ GIS)

7. Mutual understanding and mapping of metadata $(\mathrm{BIM} \leftrightarrow \mathrm{GIS})$

8. Propagation of quality information in exchange processes $(\mathrm{BIM} \leftrightarrow \mathrm{GIS})$

\section{Service-level-opportunities:}

9. Clarify the term "service" (BIM $\leftrightarrow$ GIS)

10. Adapting existing GIS services for BIM (BIM $\leftarrow$ GIS)

11. Data templates for geo-entities based on ISO 12006-3 $(\mathrm{BIM} \leftrightarrow \mathrm{GIS})$

\section{2. $\mathrm{CDE}$ API for geo-feature (BIM $\leftarrow$ GIS)}

Within the JWG14 the listed opportunities were the basis for an internal discussion and for the eventually suggested new work items.

\subsection{Suggestions for further (standardization) work}

The possibilities listed in the above subsection 3.6 were then arranged by the JWG14 in such a way that three specific recommendations for further standardization projects were formulated as the end result of the committee work.
1. Linking abstract concepts in BIM and GIS standards. The incompatibility of conceptual schema languages and conceptual models should be investigated. Then transformation rules or an ontology should allow schema crosswalks. Ontology linksets can define links and transformations between equivalent concepts.

2. Geospatial and BIM dictionary. A dictionary with terms in the two domains closes the gap between the two domains, because individual terms are only used within one domain or understood differently between the domains. In addition, BIM/GIS integration can again require new terms. A BIM/GIS dictionary would prevent future (translation) work and improve the understanding of terms between professional engineers.

3. Information exchange guidelines between BIM and GIS. This suggested work item does not aim to develop new standards but provide guidelines on how to use existing standards adequately. The instructions refer to: Georeferencing of BIM models, reduced complexity and limited data types for data transfer from BIM to GIS (GeoEIR), GIS quality model to meet high geometric and semantic requirements for BIM, metadata to support the bidirectional BIM/GIS information exchange and quality change in the process of information exchange.

\section{INTERPRETATION AND FURTHER WORK}

From the author's point of view, all suggestions for further standardization work are relevant. However, Suggestion 1 (ab- 
stract concepts) is more academic in nature and requires a high level of knowledge in information modeling. Suggestion 2 (dictionary) is a typical standardization task, namely a codification of already established terms. Currently (January 2022) the ISO/TC59/SC13 has put the proposed standardization project Technical report "Geospatial and BIM - review of vocabularies" to vote. It is to be included in the work program of the TC. The national committees now have to decide whether they welcome the project and / or participate with delegated experts.

Suggestion 3 (guidelines) is particularly important from a practical point of view of BIM/GIS integration. Often the existing standards are not known in practice or the standards (especially the GIS standards) are very abstract and technical. Guidelines can help to actually apply the standards and thus contribute to better interoperability between data, services, processes and business models of the BIM and geospatial domains.

This article focuses on BIM / GIS standardization. But standardization is not an end in itself. Standards shall provide fair market access and help the economy to grow. In the outlook, the necessity of BIM / GIS interoperability should now be illustrated using two examples from the author's personal work.

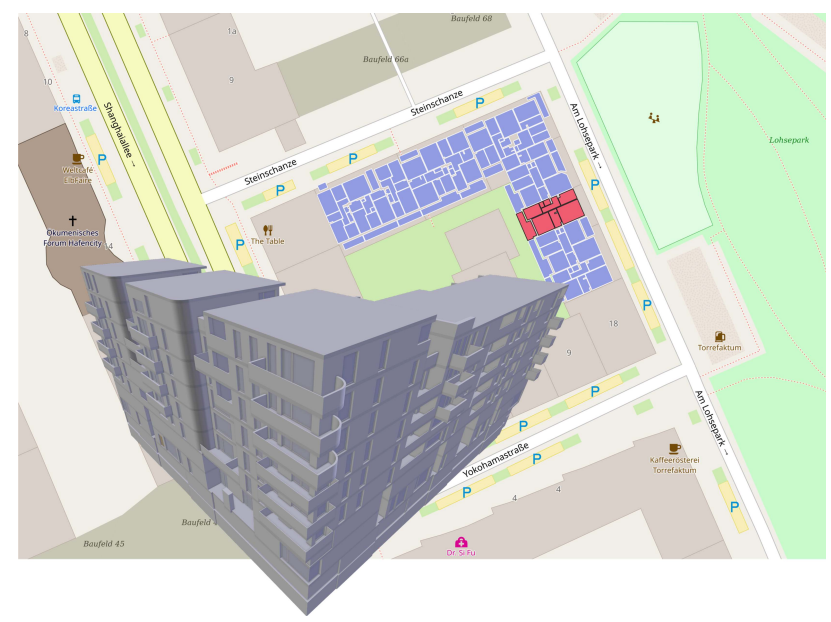

Figure 3. In this practical example, the floor plan of residential buildings (BIM) is shown on the map. This software feature would have been much easier to achieve with better BIM / GIS standards. Figure from (Clemen and Roxin, 2020)

Figure 3 shows a demonstrator developed at HTW Dresden. As part of the IMMOMATIK research project, the BIM method was applied to the operation of real estate in the housing industry. The innovative core of IMMOMATIK is to enable a BIM/GIS-combined database query, because the facility management affects both the interior (apartment, corridor, etc.) and the exterior (e.g. garden, parking lots, etc.).

The BIM data is kept exclusively with open source software in BIMServer.org (IFC) while the geodata is kept in a PostGIS database. This allows the advantages of the respective system to be better used. Figure 3 shows that the floor plan of the building can be georeferenced and semantically annotated on an Open Street Map map. However, for the software development and the planned commercial use, a strictly standardized georeferencing of the IFC files would have been very helpful. Also a uniform shape reconstruction from the 3D-building components (IFC) of the floorplan profile would have been very helpful.

Figure 4 shows the commercial product Korfin $\odot$ developed

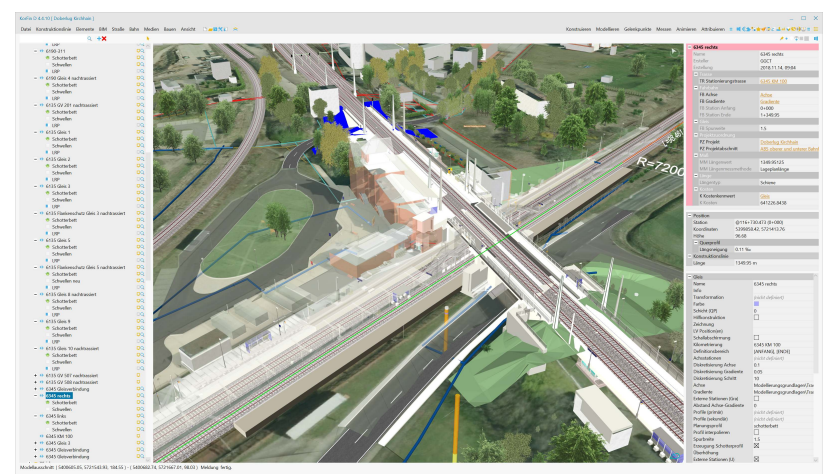

Figure 4. The figure shows the commercial software Korfin( $)$ during the joint geometric, topological and semantic analysis of environmental (GIS) and building models (BIM).

Figure from (Clemen and Roxin, 2020)

by AplusS ${ }^{5}$. The visualized integration of environmental data (GIS) and railway systems (BIM) in a planning tool makes it clear that software companies are already offering technically efficient products that are used in numerous construction projects. But software companies and their customers can also benefit from improved BIM/GIS standards, as the checking, linking and evaluation of heterogeneous geographic and building models can currently only be carried out semi-automatically.

The two examples show, that better BIM/GIS-interoperability standards would significantly accelerate business processes and make them more profitable.

\section{REFERENCES}

Beck, S. F., Abualdenien, J., Hijazi, I. H., Borrmann, A., Kolbe, T. H., 2021. Analyzing Contextual Linking of Heterogeneous Information Models from the Domains BIM and UIM. ISPRS International Journal of Geo-Information, 10(12). https://www.mdpi.com/2220-9964/10/12/807.

Breunig, M., Bradley, P. E., Jahn, M., Kuper, P., Mazroob, N., Rösch, N., Al-Doori, M., Stefanakis, E., Jadidi, M., 2020. Geospatial Data Management Research: Progress and Future Directions. ISPRS International Journal of Geo-Information, 9(2). https://www.mdpi.com/2220-9964/9/2/95.

Clemen, C., Görne, H., 2019. Level of Georeferencing (LoGeoRef) using IFC for BIM. Journal of Geodesy, Cartography and Cadastre, 2019(10), 15-20. https://jgcc.geoprevi. ro/docs/2019/10/jgcc_2019_no10_3.pdf.

Clemen, C., Roxin, A., 2020. Bridging the Gap between Geospatial and Construction. Geo4Construction 2020, 2020. https://www.geo4construction.com/content/article/bridgingthe-gap-between-geospatial-and-construction.

EN 17412-1, 2020. Building Information Modelling - Level of Information Need - Part 1: Concepts and principles. Standard, European Committee for Standardization, Brussel, BE.

Gilbert, T., Rönsdorf, C., Plume, J., Simmons, S., Nisbet, N., Gruler, H.-C., Kolbe, T. H., van Berlo, L., Mercer, A., 2020. Built environment data standards and their integration: an analysis of IFC, CityGML and LandInfra. Technical report, buildingSMART International. Accessed: 2021-01-13.

\footnotetext{
5 https://www.apluss.de/welcome.html
} 
Herlé, S., Becker, R., Wollenberg, R., Blankenbach, J., 2020. GIM and BIM: How to Obtain Interoperability Between Geospatial and Building Information Modelling? PFG - Journal of Photogrammetry Remote Sensing and Geoinformation Science, $88,33-42$.

Hijazi, I., Donaubauer, A., 2017. Integration of building and urban information modeling-opportunities and integration approaches. Geoinformationssysteme 2017 -Beiträge zur 4. Münchner GI-Runde, Thomas Kolbe and Ralf Bill and Andreas Donaubauer.

ISO 11354-1, 2011. Advanced automation technologies and their applications - Requirements for establishing manufacturing enterprise process interoperability - Part 1: Framework for enterprise interoperability. Standard, International Organization for Standardization, Geneva, $\mathrm{CH}$.

ISO 12006-3, 2007. Building construction - Organization of information about construction works - Part 3: Framework for object-oriented information. Standard, International Organization for Standardization, Geneva, $\mathrm{CH}$.

ISO 16739-1, 2018. Industry Foundation Classes (IFC) for data sharing in the construction and facility management industries - Part 1: Data schema. Standard, International Organization for Standardization, Geneva, $\mathrm{CH}$.

ISO 19101-1, 2014. Geographic information - Reference model - Part 1: Fundamentals. Standard, International Organization for Standardization, Geneva, $\mathrm{CH}$.

ISO 19103, 2015. Geographic information - Conceptual schema language. Standard, International Organization for Standardization, Geneva, $\mathrm{CH}$.

ISO 19107, 2019. Geographic information - Spatial schema. Standard, International Organization for Standardization, Geneva, $\mathrm{CH}$.

ISO 19109, 2015. Geographic information - Rules for application schema. Standard, International Organization for Standardization, Geneva, $\mathrm{CH}$.

ISO 19111, 2019. Geographic information — Referencing by coordinates. Standard, International Organization for Standardization, Geneva, $\mathrm{CH}$.

ISO 19650-1, 2018. Organization and digitization of information about buildings and civil engineering works, including building information modelling (BIM) - Information management using building information modelling - Part 1: Concepts and principles. Standard, International Organization for Standardization, Geneva, $\mathrm{CH}$.

ISO 21597-1, 2020. Information container for linked document delivery - Exchange specification - Part 1: Container. Standard, International Organization for Standardization, Geneva, $\mathrm{CH}$.

ISO 23262, 2021. GIS (geospatial) / BIM interoperability. Technical report, International Organization for Standardization, Geneva, $\mathrm{CH}$.

ISO 29481, 2016. Building information models — Information delivery manual - Part 1: Methodology and format. Standard, International Organization for Standardization, Geneva, $\mathrm{CH}$.
Jaud, Š., Donaubauer, A., Heunecke, O., Borrmann, A., 2020. Georeferencing in the context of building information modelling. Automation in Construction, 118, 103211. http://www.sciencedirect.com/science/article/pii/S0926580519311896.

Jetlund, K., 2021. Harmonizing and linking conceptual models of geospatial information: Technologies for information modelling in GIS, ITS and BIM. dissertation, NTNU - Norwegian University of Science and Technology.

Karimi, S., Iordanova, I., 2019. Integration of BIM and GIS for Construction Automation, a Systematic Literature Review. Archives of Computational Methods in Engineering, 28. https://doi.org/10.1007/s11831-021-09545-2.

Noardo, F., Arroyo Ohori, K., Biljecki, F., Ellul, C., Harrie, L., Krijnen, T., Kokla, M., Agugiaro, G., Stoter, J., 2020. Geobim benchmark - isprs scientific initiative 2019 - final report. Technical report, ISPRS.

Roxin, A., Hbeich, E., 2019. Semantic interoperability between BIM and GIS - review of existing standards and depiction of anovel approach. 36th CIB W78 - Information Technology for Construction, hal-02279633. https://hal.archivesouvertes.fr/hal-02279633.

van Berlo, Leon an Krijnen, T., Tauscher, H., Liebich, T., van Kranenburg, A., Paasiala, P., 2021. Level of Georeferencing (LoGeoRef) using IFC for BIM. Proceedings of the 38th International Conference of CIB W78, Luxembourg, 13-15 October, 123-137. https://itc.scix.net/paper/w78-2021-paper-013. 